\section{Trade in Health Service: Unfair Competition of Pharmaceutical Products in Nepal}

Madhusudan Subedi

\begin{abstract}
About 35 percent of the total demand for medicines in Nepal is covered by Nepali Pharmaceutical companies, and such companies are moving ahead for producing different kinds of medicines. The Government of Nepal, Department of Drug Administration (DDA) has formulated different regulations and guidelines to ensure ethical practices in the medical sector of Nepal. Ethical Promotion of Medicine-2007 was developed and released to encourage the improvement of health care through the rational use of medicine and discourage unethical practices. It is distressing that the guidelines have not been implemented properly due to the conflict of interests among concerned stakeholders. The cost of medicine has been very expensive and poor people have always suffered.
\end{abstract}

Key Words: Bonus, Ethical Guideline, Unethical Practices, Pharmaceutical Regulation, Conflict of Interest

\section{Introduction}

Pharmaceuticals are indispensable to health systems; by complementing other types of health care services they can reduce mortality and morbidity rates and enhance quality of life. Therefore, access to health care and essential medicines is increasingly being viewed as a fundamental human right (WHO 2009). Yet the abilities of pharmaceuticals to save lives, reduce suffering and improve health depends on their being of good quality, safe, available, affordable and properly used. It is estimated that one third of the global population do not have regular access to essential medicine. Furthermore, one third of developing countries either have no regulatory authority or only limited capacity to regulate the medicines market (WHO 2009).

The pharmaceutical sector is highly vulnerable to corruption and unethical practices (WHO 2009; WHO 2006), due in part to the high market value of pharmaceutical products. Moreover, the stakeholders involved are numerous, diverse and have different objectives. They include manufacturers, wholesalers, retailers, prescribers, sales representatives, regulators, policy makers and researchers.

The pharmaceutical industry applies a large proportion of its resources to marketing and advertizing operations (Petryna and Kleinman 2006). One central issue in the debate about the pharmaceutical industry has been whether it is primarily driven by innovation or marketing. Information about promotional expenditures of the pharmaceutical companies is rarely available and is questioned by the public health expert and Consumer Rights Activists. A majority of critics of the pharmaceutical policy in developing countries seem to favor a drastic regulation of health services, including pharmaceuticals (Van der Geest 1984). Their basic idea is that the profit maximization is by definition pathogenic because it puts profit before people. The structure of relations between manufacturers and the supply chain (the importer, wholesaler and retailer), between manufacturer and prescriber, involves something more like reciprocal access to guarded resources (Lakoff 2006). Prescription drug promotion practices that involve giving financial grants and valuable items to doctors and retailers are common in Nepal (Subedi 2001; GAPN 2007; Thapa 2007). The Government of Nepal, Department of Drug Administration (DDA), has 
developed and released Guidelines on Ethical Promotion of Medicine-2007 with the objective to enhance ethical promotion of medicine to support and encourage the improvement of health care through the rational use of medicine and discourage unethical practices. The guidelines, however, could not properly be implemented due to the conflict of interests among various stakeholders. In a complex system such as pharmaceutical trade, there are so many vested interests and players blame to another groups but not reflect critically on one's own practice (Harper and Jeffery 2009). This paper describes the historical context of Ethical Guidelines and interests of various stakeholders, focusing particularly on the issue of bonuses or gifts. This is not only interesting for producers, distributors and retailers, but also one of the major concerns of the state and the general public.

\section{Methods and Materials}

On July $17^{\text {th }} 2007$, DDA released its Guidelines on Ethical Promotion of Medicine. Nepal Chemist and Druggists Association (NCDA), one of the major stakeholders supposed to follow the Guidelines, forwarded a 12-point demand to the concerned authority to nullify the guidelines. Though NCDA is a non-governmental organization, it represents the interests of the importers, wholesalers and retailers. On August $6^{\text {th }}$ 2007, NCDA announced that it would stop import of drugs from the very next day, as part of its protest. This sensitized the issue in the public sphere. To explore the ongoing discourse and the conflicting interests of various stakeholders, a chain of various stakeholders followed. In such a context, documents and papers on the issue were being reviewed, and a series of formal and informal interactions were initiated with the key stakeholders like Association of Pharmaceuticals Producers of Nepal (APPON), Nepal Medical Council (NMC), Nepal Pharmaceutical Association (NPA), Graduate Pharmacist
Association-Nepal (GPAN), Nepal Chemist and Druggist Association (NCDA), Nepal Medical Association (NMA), Nepal Pharmacy Council and Nepal Medical and Sales Representative Association (NMSRA), and Department of Drug Administration (DDA) to understand and explore the crux of the problem for implementing the guidelines. Some people were interviewed once and some were interviewed more than twice depending upon their response with other stakeholders. The responses and interests of various stakeholders were analyzed and are presented in this paper.

\section{Results and Discussion}

Thus, the paper starts from contexts of the guidelines and explores the discourse of various organizations involved during the formulation of ideas, preparation of draft report and the challenges faced during the implementation of the guidelines.

\subsection{Context of the Guidelines}

The distribution of imported medicines in Nepal started much earlier than the manufacturing of allopathic medicine in Nepal. It is only after 1950s that it was attempted to start manufacturing allopathic medicine in Nepal. The geographical market integration of the country brought by the construction of the east-west highway and other link roads paved the way for opening of scope for pharmaceutical companies. By the end of July 2008, there were 42 allopathic medicine manufacturer and repacking companies, out of which 12 were WHO-GMP certified. A total of 4970 foreign and 2768 domestic pharmaceutical products are authorized for marketing in Nepal. This market has ample opportunity with a growth rate of $16.1 \%$ per annum and a market share of approximately 35\% in the present context (Gorkhali 2008).

The Drug Act of 1978 was promulgated in Nepal to prohibit the misuse or abuse of allied pharmaceutical materials as well 
as the false or misleading information relating to efficacy and use of drugs and to regulate and control the production, marketing, distribution, export-import, storage and utilization of those drugs which are not safe for the use of the people, efficacious and of standard quality. In accordance with objectives of the National Health Policy 1991, the National Drug Policy 1995 has been implemented.

In 1986, eight years after the Drug Act, the Government of Nepal published the National List of Essential Drugs based on the country's disease pattern as well as the relative merit of selected drugs in terms of cost, safety, and efficacy. Further, this step was taken in response to the request of WHO to all member countries to have a list of essential drugs as per the country's need. This list was revised in 1992, 1997 and 2002 respectively. Similarly, Standards for Pharmaceutical Regulation and Care was prepared and implemented in 2002 to measure performance and to meet the requirement of people by ensuring quality in the services provided by applying indicators for monitoring. This document adapted the WHO/SEARO framework for developing health care standards. The major focus has been given to quality characteristics and standards for drug regulatory control, drug supply and management, rational drug use and safe disposal. This framework highlighted the principles for regularly controlling pharmaceutical sales promotion and advertisement by measuring the level of promotional activities, and to prevent and monitor perverse incentives for prescribers and dispensers.

Following the WHO Conference of Experts on the Rational Use of Drugs held in Nairobi in November 1985, WHO prepared a revised drug strategy which was endorsed by the Thirty-third World Health Assembly in May 1986. This strategy included, among other components, the establishment of ethical criteria for drug promotion based on the updating and extension of the ethical and scientific criteria established in 1968 by the Twenty-first World Health Assembly. The criteria that follow were prepared in compliance with the above on the basis of a draft elaborated by an international group of experts. The main objective of developing ethical criteria for medicinal drug promotion was to support and encourage the improvement of health care through the rational use of medicinal drugs.

These criteria constitute general principles for ethical standards which could be adapted by governments to national circumstances as appropriate to their political, economic, cultural, social, educational, scientific and technical situation, laws and regulations, disease profile, therapeutic traditions and the level of development of their health system. They apply to prescription and non-prescription medicinal drugs ("over-the-counter drugs"). They also apply generally to traditional medicines as appropriate, and to any other product promoted as a medicine. It was also clearly mentioned that the criteria could be used by people in all walks of life; by governments; the pharmaceutical industry (manufacturers and distributors); the promotion industry (advertising agencies, market research organizations, etc.); health personnel involved in the prescription, dispensing, supply and distribution of drugs; universities and other teaching institutions; professional associations; patients' and consumer groups; and the professional and general media (including publishers and editors of medical journals and related publications).

All these are encouraged to use the criteria as appropriate to their spheres of competence, activity and responsibility. They are also encouraged to take the criteria into account in developing their own sets of ethical standards in their own field relating to medicinal drug promotion. It is further mentioned that the criteria do not constitute legal obligations; governments may adopt legislation or other measures based 
on them as they deem fit. WHO ethical criteria cover a wide range of promotional activities like advertising, medical representatives, samples, symposia and scientific meetings, and post-marketing scientific studies.

Nepal being a small market with prospects for good scope in replacing imports has resulted in the development of industries, and the concept of bonus and special incentives has played a major role on promotional practices. This has also resulted in some unethical practices by most of the companies, including Indian companies. At this juncture DDA proposed a study about the current promotional practices of the pharmaceutical companies in Nepal, a study that was supported by WHO. The main objective of the study was to identify the current promotional practices of pharmaceutical products available in Nepal and assess the existing practices in context of WHO criteria for medicinal drug promotion and its compliance for ethical promotion.

In this regard, GPAN conducted a study on promotional practices in the Nepalese pharmaceutical market in collaboration with DDA and WHO. A total of 30 pharmaceutical companies were selected consisting of 15 domestic and 15 Indian. The findings were presented in a seminar on $3^{\text {rd }}$ February, 2007. The study found a wide variation in bonus schemes offered by the companies. In some products, for example, cardiac were found without bonus. The product like Amoxycillin and Ciprofloxacin were in the market with a free offer which ranged from 10 percent to 100 percent. Albendazole $400 \mathrm{mg}$ was another product in the market with wide a bonus range from 20 percent to 100 percent. Vitamin B complexes were in the market with as high as 60 percent bonus offer especially for $200 \mathrm{ml}$ packs. The $100 \mathrm{ml}$ packs were sold at the bonus offer half to that offered for $200 \mathrm{ml}$ packs. Even products such as cough formula, anti ORS were having a bonus system. The most commonly used bonus by every company was a 10 percent offer, and 70-100 percent as exceptional cases with certain products. However, some companies had been practicing no offer system in the sale of some selected products.

In response to the relationship between WHO-GMP certified companies and bonus offer, the study did not find any relationship; the bonus offer was equally being practiced by WHO-GMP certified companies as well as other companies. Some WHO-GMP certified companies even have been seen to offer good gift items such as TV to the prescribers. However, some of the WHO GMP certified companies are found to have the maximum bonus offer of 20 percent with no bonus offer in certain selected products. The gift items being offered were carpets, pens, blankets, bed sheets, iron, calculator, TV, etc. The companies are also found to have practiced offering a good bonus for products that DDA had already decided an irrational combination.

The companies had gone beyond ethical norms to provide a special incentive of personal benefit from the sale of products in quantity, while forgetting the issues of quality and patients' benefit. It was very clear that the maximum benefit is being taken by the retailers enjoying bonus offer and long term credit limits. The study highlighted that the substitution by the retailers on prescription to go for products with more offer had resulted some set back on turnover growth of some companies focusing their promotion on ethical prescription base. The study results indicated the need for implementation of guidelines on ethical promotion in Nepal.

Based on the research findings, the concerned stakeholders felt the need for the guidelines on ethical promotion of medicine. Guidelines on the Ethical Promotion of Medicine was drafted and discussed with various stakeholders like APPON, NMC, NPA, GPAN, NCDA, NMA, Nepal Pharmacy Council (NPC) and NMSRA, and DDA implemented them from July 17, 2007. Although the term 
promotion refers to all informational and persuasive activities by manufacturers and distributors, the effect of which is to induce the prescription, supply, purchase and/or use of medicine, the authority of DDA mentions that the commonly used unethical practice is to provide expensive gift, either in form of cash or kind to the prescriber, sponsoring pleasure trips abroad, and in form of free medicine to the retailers.

\subsection{Conflict of Interest: One Issue Many Voices}

The APPON welcomed the Ethical Guidelines and argued that this policy would help the long term benefit to the nation and its people towards making a stronger and self-reliant Nepal. The former President of APPON admitted the unethical practices of medicine in Nepal:

"Of course, the unhealthy practices are rampant in the country while selling and marketing drugs....There is a glaring trend to offer free goods and bonuses to the retailers. If to compare with the neighboring India, this sort of trend is more prevalent in Nepal. Only the certain number of companies is reaping undue advantaged at the cost of entire health sector of the country. This is also sure to hamper the ethical expansion of pharmaceutical companies. Nepali pharmaceutical companies are offering more commission to retailers than Indian companies of the same nature. This strategy adopted by the domestic pharmaceutical company is gravitated towards the promotion of domestically manufactured drugs (Vaidya 2008:4).

He also acknowledges that pharmaceutical companies tend to bribe doctors to prescribe their medicines. He feels that without visionary interactions among all the stakeholders engaged in pharmaceutical sector, the sector cannot witness dynamic development. The current President of APPON confesses, for example:

Ideally code of conduct should come from within and it should not be imposed upon by any agencies. In the absence of any such activity from private sector, Government of Nepal took lead in this matter and held round of discussions with all stakeholders before actually implementing the ethical guideline on pharmaceutical marketing. The problem started when the major stakeholder backed out and openly defied the government decision. This led to chaotic situation in the pharmaceutical market (Shrestha 2008:64)

During the informal dialogue with the manufacturers, most of them mentioned that individual manufacturer should be more responsible for the better implementation of the guidelines. Currently, retailers related to the trade of medicine are being entitled to $16 \%$, and wholesalers are entitled to get commission about $5-6 \%$ as per the provisions fixed by the government of Nepal. The agreement was reached between the DDA and the APPON to offer extra $10 \%$ commission in prescribed drugs and $20 \%$ in non-prescribed drugs to concerned retailers. So, why the system of giving extra incentive in the form of discount or free medicine, which could be sold, is provided to the dispenser? This is a lucrative offer to the retailers for substituting the prescription (Thapa 2007b).

NCDA, a key player in the distribution of drugs, voiced its reservation. Members of NCDA argued that some handful people, including the DDA, were trying to denigrate the reputation of NCDA by raising the issue of deal bonus in a bad light. They argued that the Ethical Guidelines talk about scraping deal bonus, but just by bringing out the Ethical Guidelines, one could not be sure that the deal bonus scheme 
would be halted and the result will not be that drug price go down. They argue that profit will be transmitted straight to the producers, not to the general people. They see DDA and APPON have been making conspiracy to victimize the retailers and argue that such regulation cannot be implemented unilaterally focusing against NCDA but rather requires more debate and discussion.

The NCDA also forwarded a 12-point demand as a prerequisite before the guidelines could be implemented. Most of the demands presented were not related to the guidelines. This action by the NCDA was in fact a strategy to cloud the issue of bonus under the eyes of the consumer. NCDA even circulated a notice to its members (retailers and distributors) stating that they would refrain from importing, distributing and selling drugs in case the government did not look into their demands. A memorandum to this effect was also handed out to the Health Secretary and Health Minister. This resulted in a meeting of NCDA with the Health Ministry officials whereby the ministry agreed to look into their demands in a positive light. However, this action on the part of the NCDA should be seen as another stumbling block since it was able to distort the context and delay the implementation of the guidelines. Regarding this agreement a leading consumer activist contended that the Health Ministry had overstepped its jurisdiction. He affirmed that the decision taken by the Minister by giving in to the pressure put forth by NCDA went counter to the authority that lay with Drugs Decision Committee (DDC) of the DDA and that such an action implies policy corruption.

During my interaction with Executive Committee Members of NCDA, they repeatedly mentioned the country's health situation and also some issues mentioned in the Guidelines. Some members also mentioned that the Guidelines are very advanced, and therefore, could be implemented only in advanced countries like USA, UK and Japan. When further asked about how to improve the situation, the simple answer was to have a medical line less corrupt, and more service oriented and people focused.

The Chief of DDA's view is that a written code of ethics is required for the uniformity in conduct (Thapa 2007b). The authority of DDA mentioned that the document should have been made by the companies and it is not something that the government needs to do. In Nepal, none of the companies took the initiative to make such a document, and there were a lot of anomalies in the market after the government adopted a liberal policy in the pharmaceutical industry, and as a result the government has not paid so much attention to the prices.

Despite its professional demand and some reservations on the guidelines, the views of NMSRA are quite positive towards the Ethical Guidelines. During the interaction with the President of NMSRA, for example, he said:

Positive point of the ethical guidelines is that the foreign companies exporting their products to Nepal should either open their office in Nepal or the importer is made responsible on their behalf. It is also mentioned that the Name of the chief of the marketing of domestic as well as foreign companies must be provided to the DDA and any change of person should be notified as soon as possible. If DDA implements this properly along with the registration of MRs, $60 \%$ of the ethical concern will be solved. For the remaining 40\% concerns are related to the behaviors of the prescribers and the retailers.

He mentioned that the benefits and salaries of the medical representatives (MRs) are determined based on the sales volume of the drugs of the particular company. In order to increase the volume of sales of a specific company, MRs 
used to to go to wholesalers and the retailers, are under undue pressure from Indian companies to meet their targets, performance oriented and doctors are increasingly demanding more and more elaborate gifts before they behave in ways that will let the MRs meet their targets (Harper and Jeffery 2009). President of NMSRA further said:

In order to avoid over promotion, the main part of the remuneration of the medical representatives should not directly related to the volume of the sales. But in practices, this has been happening in Nepal. Most of the Medical Representatives should fulfill their quota. If we are able to sale our product above than the quota provided, we get some kind of reward. If we are unable to fulfill the given quota, our job is at risk. If such situation continues, ethical promotion of medicine becomes like a dream.

Members of the NMSRA have the view that implementation of the guidelines would help reduce the price of medicine and the general people would benefit directly. If the bonus is just removed, the benefit goes only to manufacturers. "APPON seems positive towards the Ethical Guidelines because manufacturers want to cut down the bonus, but they don't want to revisit their price which is unfair", said Central Committee Member of NMSRA

The concern of NMSRA seems to be about the price of medicine. If the bonus is cut, the price of the medicine should be cut down and the people should get cheaper medicine. NMSRA members mentioned that bonus varies from one company to another, one brand to another, one category to another. Generally for the India Companies, bonus is about $20 \%$ for OTC drugs, and 10\% for Antibiotics. They hardly give bonus for lifesaving drugs. They don't see such consistency in Nepali companies.
The views of NMC are straightforward. Former Registrar of NMC mentioned that some doctors might have a very good relationship with the specific companies, brand and products. They might trust one specific company based on their own experience and not because of the gift and other benefits. Other people could say that Dr. $\mathrm{X}$ is getting advantage from the company $\mathrm{Y}$ so that he/she prescribes a specific brand. This might not be true. The former Registrar said:

DDA is the main responsible body for the quality control but it has its own limitations. Inadequate human resource, incompetent human resource, lack of the support from other stakeholders and lack of the commitment of the people who are responsible for the various activities are some of the limiting factors of DDA. Likewise, APPON should monitor about the fair business within the companies. One of the important points is that we are still depending upon the Indian companies and Multi National Companies, they have their business policy and we have not been able to enforce them for the ethical promotion of pharmaceutical products. We even do not know their promotional strategies.

Members of the NMC believed that that the objective of the ethical guidelines would be to promote the rational use of medicine and discourage the unethical practices, and to promote healthy business among producers by not compromising the quality of medicines. The NMC's opinion is that after developing the clear cut guidelines and implementing them properly, we can give moral pressure to the Indian companies and multinational companies.

Another stakeholder, NMA fully supports the move of DDA to ensure ethical practice in the country's medical sector. 
Responding to the rumor that doctors demand gifts and other benefits from the companies to prescribe their brands, the President of NMA said:

The blame that majority of the doctors unethically take bribes from some pharmaceutical companies to prescribe their drugs do not hold any ground. While entering into the profession, the doctors take an oath to perform their duties with humanity, compassion, and dedication to the welfare of the sick people according to the best of their ability and judgment. To promote their brand, medical representatives provide samples of medicine to the doctors, which is not unethical. Some companies give calendars, pens, diary to the doctors. This has been very common these days. This is not secret and is widely acceptable all over the world.

He mentioned that the main players of the guidelines are the manufacturers and the retailers. If the ethical guidelines were implemented, the price of the medicine would certainly decrease. He further said:

Doctors are not demanding the gifts, retailers are not demanding the gifts but manufacturers are pushing their drugs by giving the gifts to the doctors and bonus to the retailers. This should be stopped as soon as possible. It has been very urgent to develop prescription substitution control mechanism particularly prescription substitution prone areas like major hospital.

NMA, however, accepts that pharmaceutical companies provide small support for the workshops and professional meetings of the doctors. This does not mean that the doctors are supposed to prescribe, recommend or promote their brands.

\subsection{Price, Substitution and Consumer Health}

Despite the numerous positive aspects of the guidelines only the issue of 'bonus' has taken centre stage in the debate. The issue of bonus can also be linked to the price of medicines and accompanying practices associated with the sales of medicines to the consumers. It is difficult for a person to know the reasonable price of a medicine. The price of the very same medicine, but of different brands, is often different. There are various factors influencing the price, but the variation should be within the tolerable limit (Thapa 2007a). It is obvious that if the bonus is cut, also the price of the medicine should be cut, to the benefit of the buyers, i.e. the people.

The tremendous variation in the price of the medicine may affect the trust in the quality of medicine. Sometimes a price increase is due to unreasonable expenses on market promotion. Commenting on the scenario of drugs distribution and sales in Nepal, General Secretary of Consumer Rights argues that bonus, gifts to doctors, expenses rendered for travel and seminar to doctors are rife and which ultimately is borne by the consumer. Citing an example from the Pokhara Zonal Hospital which has rented out space to a private pharmacy for Rs. 1 million, he claims that the law categorically states that each hospital needs to run its own pharmacy. Furthermore, by pointing to irregularities in the drug distribution and sales regime, drug pricing, fake drugs and lack of monitoring from the government, the General Secretary further argues that the decision taken by the government on August 2007 further compounds the already deteriorating system of drug distribution and sales in Nepal. 
Regarding the issue that bonus is provided to retailers, some argue that the consumer should ask for a discount when purchasing medicine. It is better to provide a reasonable price rather than creating a situation where a consumer can ask for a discount. Quality medicine at reasonable prices should be the motto for all pharmaceutical industries (Thapa 2007a). Some unethical trends in the market promotion of medicine have not only increased concern among the consumers, but also among those who practice them. As many products from various manufacturers have the similar feature, the easiest way of market promotion is the persuasive action targeting the prescribers and/or the drug retailers. Substitution of medicines to the consumers is rife and the issue of bonus directly impinges on this practice. The pharmaceutical practice of selling drugs to the consumers is such that substitution is rampant for drugs that come with huge bonuses. This has also led to the market for pharmaceuticals to be promoted unethically. Lucrative offer to prescriber may insist over prescription and to retailer may encourage prescription substitution and dispensing without prescription.

After the guidelines were introduced by DDA, it also made an effort to reduce the price of some of the medicines. The prices for the medicines were published in the Gorkhapatra National Daily. People were expecting a cut in the price of medicine, at least from Nepali manufacturers, but it did not happen.

\subsection{Challenges to Implement the Guidelines}

The Guidelines do not have any legal status, so practice is 'voluntary', one can either abide by them or not abide at all. There is still confusion regarding the importers. So, the status of the guidelines as of now is that their effect is 'very partial' and that Nepal has to wait a few years to see the results of the guidelines. The DDA tried to call for one or two meetings and then thrash out what needs to be changed and it had been recording what needed to be changed as well. Currently, the person who had been trying to implement the Ethical Guidelines transferred to another section under the Ministry of Health and Population.

The Government should be willing to revise the Guidelines and to make them mandatory Act. All the margins should be transparent, for the wholesalers as well as retailers, but there should not be any under-the-table activities. Hence to regulate ethical marketing, regulators also must improve the capacity, training and expertise to act on complaints from the public, voluntary organizations, and from within the pharmaceutical industry (Raut 2008). Internal training, promotional practices and post-market surveillance systems within pharmaceutical companies must be subjected to regulatory audit.

The existing publications are almost entirely concerned with the macrostructures of drug distribution; the actual users of pharmaceuticals hardly come into the picture (Van der Geest 1984). Sometimes the rational drug policy may not always be in the interest of the policymaking elites in Nepal. The group of consumers who know about people's health condition and their economic position may play in the network of economic and political relationship and would be able to explore the options that can be approached for consumer action. Anthropologists can add important information in this respect.

\section{Conclusion}

Effective functioning of a pharmaceutical system is dependent on the transparency of the process, and ability to hold individuals and entities accountable for adhering to standard procedures, norms, laws and regulations in each one of these functions. When the medicines are prescribed and dispensed more for the financial interests of the prescribers 
and dispensers than for the needs of the patients, this prevents public accountability. By informing consumers on quality, price and efficiency of drugs and strengthening their position, the pharmaceutical companies can be forced to adapt fair business. The crucial issue is, of course, awareness of consumer rights who can be mobilized to resist the unethical marketing strategies of pharmaceuticals and drug traders. The regulatory bodies would not be able to implement the public's concerns, especially those that affect the belowpoverty level population in Nepal. If the proactive initiations are taken to regulate the Nepali pharmaceutical market in an ethical manner, the country's health sector will grow at a healthy clip. Without increasing the transparency and accountability in the matters of drug registration, production, promotion, distribution, prescription and pricing the issues of public health and consumer rights will remain tangential.

\section{Acknowledgements:}

This paper emerged from the broader collaborative research project 'Tracing Pharmaceuticals in South Asia' conducted by University of Edinburgh and Martin Chautari, funded by DFID/ESRC. I would like to thank Prof. Roger Jeffery, Coordinator of the Project, and Ian Harper and Nabin Rawal, the research team of Nepal. I thank Prof. Marit Bakke for her helpful comments and suggestions.

\section{References}

Gorkhali, Mahesh (2008). Message. In Souvenir of Nepal Pharma Expo 2008. Kathmandu: APPON

Harper, Ian and Roger Jeffery (2009). Trust, Ethics and Spurious Medicine. Himal South Asia, Vol.22, No.8, Pp 31-34

Lakoff, Andrew (2006). High Contact: Gifts and Surveillance in Argentina (pp 111-135). In Adriana Petryna, Andrew Lakoff and Arthur Kleinman (eds.) Global Pharmaceuticals: Ethics, Markets, Practices. Durham: Duke University Press.
Petryna, Adriana and Arthur Kleinman (2006). The Pharmaceutical Nexus (pp 1-32). In Adriana Petryna, Andrew Lakoff and Arthur Kleinman (eds.) Global Pharmaceuticals: Ethics, Markets, Practices. Durham: Duke University Press.

Raut, Ranjan Bahadur (2008).Ethical Marketing of Pharmaceutical Products-Importance \& Relevance in Nepalese Context. In Souvenir of Nepal Pharma Expo 2008. Pp 55-6. Kathmandu: APPON

Shrestha, Umesh Lal (2008). Code of Conduct for Ethical Marketing in Nepal. In Souvenir of Nepal Pharma Expo 2008. Pp 64. Kathmandu: APPON

Subedi, Madhusudan (2001). Medical Anthropology of Nepal. Kathmandu: Udaya Books.

Thapa, Bhupendra Bahadur (2007a). Editorial. Drug Bulletin of Nepal, Vol. 18, No. 2, Pp 3-4.

Thapa, Bhupendra Bahadur (2007b). Editorial. Drug Bulletin of Nepal, Vol. 19, No. 1, Pp 3-4.

Vaidya, Pradeep Man (2008). Replacing Indian Drugs is Our Major Focus. Business World, Volume 55, Pp 4-5.

Van der Geest, Sjaak (1984). Anthropology and Pharmaceuticals in Developing Countries. Medical Anthropology Quarterly, Vol.15, No, 4, pp 87-90.

WHO (2009). Measuring Transparency in the Public Pharmaceutical Sector: Assessment Instrument. Geneva: WHO

WHO (2006). Measuring Transparency in Medicines Registration, Selection and Procurement: Four Country Assessment Studies. Geneva: WHO 